Supporting information for:

\title{
Comparison of Photocrosslinkable Gelatin Derivatives and Initiators for Three-Dimensional Extrusion Bioprinting
}

Thomas J. Tigner, $\dagger$ Satyam Rajput, $\dagger$ Akhilesh K. Gaharwar, $\dagger,+\neq$ Daniel L. Alge $*,+,+$

$\dagger$ Department of Biomedical Engineering, College of Engineering, Texas A\&M University, 77840 College Station, Texas, United States

tDepartment of Materials Science and Engineering, College of Engineering, Texas A\&M University, 77840 College Station, Texas, United States

GelNB ${ }^{1} H$ NMR:

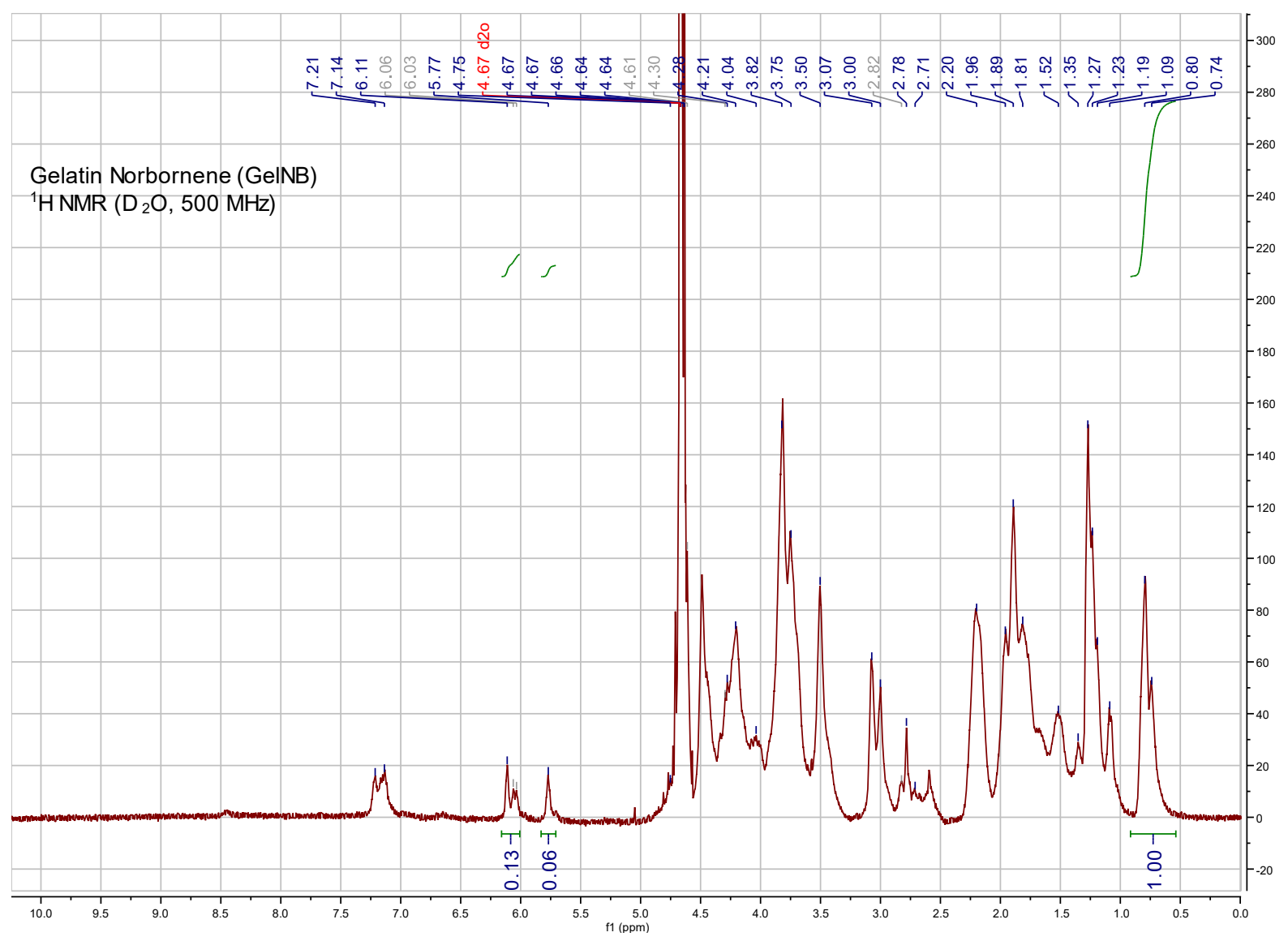

Figure S1. ${ }^{1} \mathrm{H}$ NMR of GelNB. Alkene associate peaks $\left(\mathrm{I}_{6.11}, \mathrm{I}_{5.77}\right)$ were normalized to the methyl associated peak ( $\mathrm{I}_{0.74)}$. 
GelMA ${ }^{1} H$ NMR:

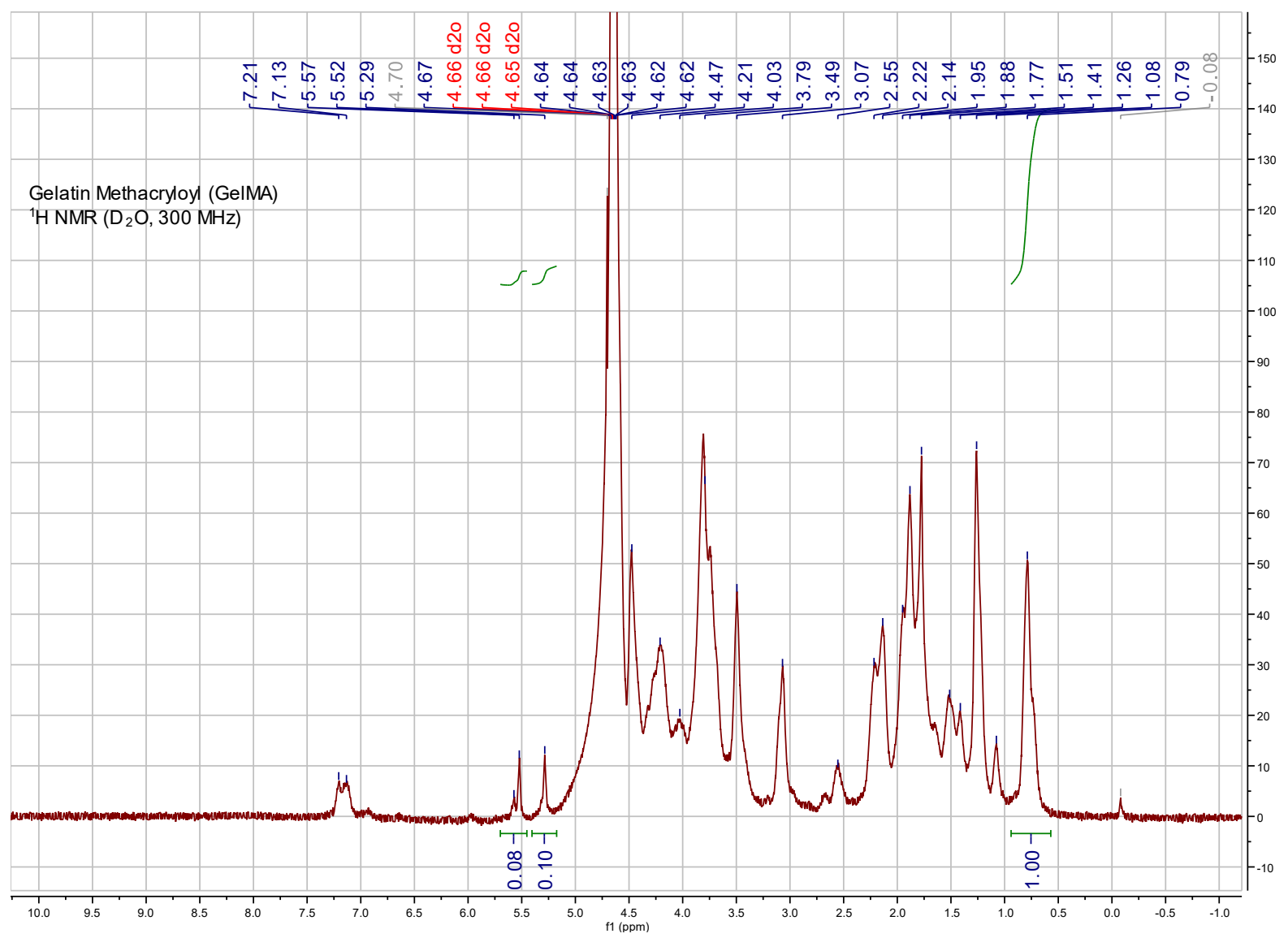

Figure S2. ${ }^{1} \mathrm{H}$ NMR of GelMA. Alkene associate peaks $\left(\mathrm{I}_{5.57}, \mathrm{I}_{5.52}, \mathrm{I}_{4.67}\right)$ were normalized to the methyl associated peak $\left(\mathrm{I}_{0.79}\right)$.

\section{GelNB Degree of Functionalization Equation:}

Functionalization equations were derived using the general methods described by van Hoorick et $a l .{ }^{1}$ and the gelatin amino acid content provided by Claaben et al. ${ }^{2}$ Equation S1 describes the degree of functionalization of GelNB, where $\mathrm{DF}_{\mathrm{NB}}$ is the concentration of $\mathrm{NB}$ in mmol per $\mathrm{g}$ gelatin, and Ix are the integrals of peaks centered at the corresponding subscript on NMR spectra. 
There are $2 \mathrm{mmol}$ alkene $\mathrm{H} / \mathrm{mmol}$ norbornene, $6 \mathrm{mmol}$ methyl $\mathrm{H} / \mathrm{mmol}$ methyl-containing amino acids, and $0.523 \mathrm{mmol}$ methyl-containing amino acids/g gelatin.

Equation S1 $\quad D F_{N B}=\frac{\frac{I_{6.11}+I_{5.77}}{2}}{\frac{I_{0.74}}{6 * 0.523}}=1.57 * \frac{I_{6.11}+I_{5.77}}{I_{0.74}}$

GelMA Degree of Functionalization Equation:

Equations S2 for the degree of functionalization of GelMA was derived using the same methods and values as in the derivation of Equation S1.

Equation S2 $\quad D F_{M A}=\frac{\frac{I_{5.57}+I_{5.52}+I_{5.29}}{2}}{\frac{I_{0.79}}{6 * 0.523}}=1.57 * \frac{I_{5.57}+I_{5.52}+I_{5.29}}{I_{0.79}}$

Computation of Extrusion Speed from Slic3r Generated G-codes:

Equation S3 was used to determine extrusion speeds (the speed at which the plunger compresses ink in the extruder) from Slic3r generated G-codes.

Equation S3 Extrusion Speed $=\frac{F E}{\sqrt{\left(X_{\text {current }}-X_{\text {previous }}\right)^{2}+\left(Y_{\text {current }}-Y_{\text {previous }}\right)^{2}}}$

Where $\mathrm{F}$ is the print speed in $\mathrm{mm} \mathrm{min}^{-1}$ specified in Slic3r. For a given line of the generated Gcode, $\mathrm{E}$ is the extrusion length in $\mathrm{mm}$ specified in that line, $\mathrm{X}_{\text {curent }}$ and $\mathrm{Y}_{\text {current }}$ are the nozzle positions in $\mathrm{mm}$ specified in that line, and $\mathrm{X}_{\text {presvious }}$ and $\mathrm{Y}_{\text {previous }}$ are the nozzle positions in $\mathrm{mm}$ 
specified in the line immediately prior to that line. Extrusion speed will be given in $\mathrm{mm} \mathrm{min}^{-1}$. The extrusion multiplier in Slic3r was used to linearly adjust the ratio of print speed:extrusion speed.

GelMA Biomaterial Ink Temperature Sweeps:

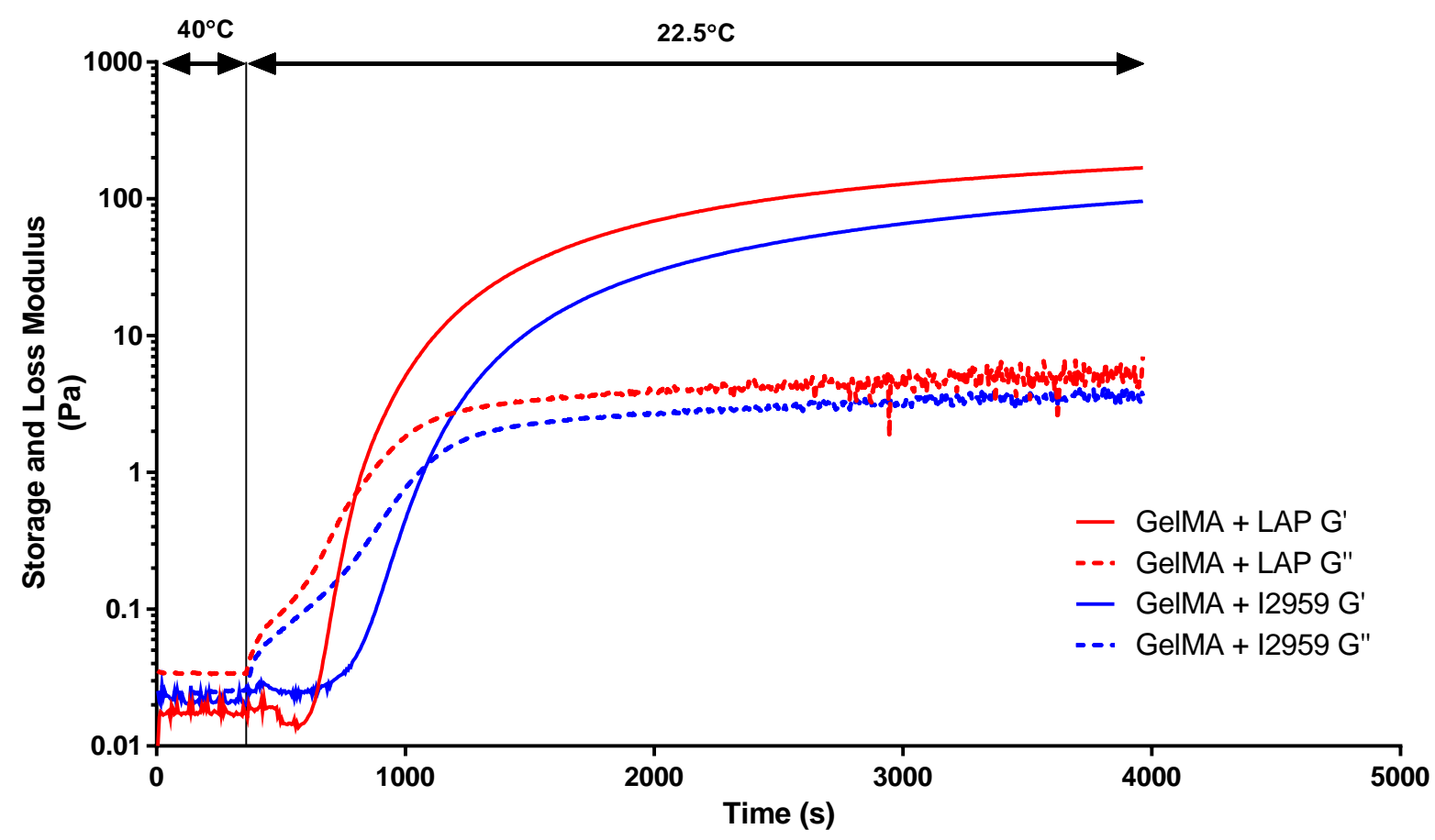

Figure S3. Rheological temperature sweeps of GelMA biomaterial inks prior to photocuring. Inks were deposited on the rheometer stage and allowed to soak at $40^{\circ} \mathrm{C}$ for three minutes before the temperature was decreased to $22.5^{\circ} \mathrm{C}$. Physical gelation kinetics at $22.5^{\circ} \mathrm{C}$ were monitored as a function of time. 


\section{REFERENCES}

1. Hoorick, J.; Gruber, P.; Markovic, M.; Rollot, M.; Graulus, G.-J.; Vagenende, M.; Tromayer, M.; Erps, J.; Thienpont, H.; Martins, J. C.; Baudis, S.; Ovsianikov, A.; Dubruel, P.; Vlierberghe, S., Highly Reactive Thiol-Norbornene Photo-Click Hydrogels: Toward Improved Processability. Macromolecular Rapid Communications 2018, 39 (14), 1800181.

2. Claaßen, C.; Claaßen, M. H.; Truffault, V.; Sewald, L.; Tovar, G. E. M.; Borchers, K.;

Southan, A., Quantification of Substitution of Gelatin Methacryloyl: Best Practice and Current Pitfalls. Biomacromolecules 2018, 19 (1), 42-52. 